\title{
Antigiardial Effect of Kramecyne in Experimental Giardiasis
}

\author{
Leticia Eligio-García, ${ }^{1}$ Elida Pontifez-Pablo, ${ }^{1}$ \\ Salúd Pérez-Gutiérrez, ${ }^{2}$ and Enedina Jiménez-Cardoso ${ }^{1}$ \\ ${ }^{1}$ Parasitology Research Laboratory, Hospital Infantil de México Federico Gómez, Dr. Márquez 162, Col. Doctores, \\ Delegación Cuauhtémoc, 06720 Ciudad de México, Mexico \\ ${ }^{2}$ Biological Systems Department, UAM Xochimilco, Calzada del Hueso 1100, Col. Villa Quietud, Delegación Coyoacán, \\ 04960 Ciudad de México, Mexico
}

Correspondence should be addressed to Enedina Jiménez-Cardoso; jimenezce@yahoo.com.mx

Received 8 August 2017; Revised 11 October 2017; Accepted 16 November 2017; Published 13 December 2017

Academic Editor: Jae Youl Cho

Copyright ( 2017 Leticia Eligio-García et al. This is an open access article distributed under the Creative Commons Attribution License, which permits unrestricted use, distribution, and reproduction in any medium, provided the original work is properly cited.

\begin{abstract}
A variety of drugs are used in giardiasis treatment with different levels of efficiency, presence of side effects, and even formation of resistant strains, so that it is important to search new only-one-dose treatments with high efficiency and less side effects. Kramecyne, an anti-inflammatory compound isolated from methanolic extract of Krameria cytisoides, does not present toxicity, even at doses of $5,000 \mathrm{mg} / \mathrm{kg}$. The objective was to determine the antigiardial effect of kramecyne over Giardia intestinalis in vitro and in vivo and analyze the expression of genes ERK1, ERK2, and AK on kramecyne treated trophozoites by Real Time Polymerase Chain Reaction (RTPCR). The median lethal dose $\left(\mathrm{LD}_{50}\right)$ was $40 \mu \mathrm{g} / \mathrm{mL}$ and no morphological changes were observed by staining with blue trypan and light microscopy; experimental gerbil infection was eliminated with $320 \mu \mathrm{g} / \mathrm{Kg}$ of weight. After treatment there were no differences between intestines from treated and untreated gerbils. Kramecyne did not have significant effect over ERK1 and AK, but there are differences in ERK2 expression $(p=0.04)$. Results show antigiardial activity of kramecyne; however the mode of action is still unclear and the evaluation of ultrastructural damage and expressed proteins is an alternative of study to understand the action mechanism.
\end{abstract}

\section{Introduction}

Giardia intestinalis is the most frequent parasite reported in children and the most frequently found protozoa in water samples [1,2]; it mainly affects children and immunosuppressed people; this protozoan presents two interconvertible forms: cyst and trophozoite. Infection is acquired by ingestion of water and food contaminated with cysts, which become trophozoites and colonize the small intestine by attachment to the epithelial microvillus $[3,4]$. Some infected people present gastrointestinal symptomatology and in many cases the disease is completely asymptomatic and the patients act as carriers releasing big quantities of cyst to the environment and promoting the transmission of infection [5].

There are several pharmaceutical agents that are used in the treatment of the giardiasis including metronidazole [6], albendazole, tinidazole, and nitazoxanide [7]; some of them are administered by one dose and others (as metronidazole) need several doses along the day for two or three days. In refractory cases by resistance or reinfection the combination of two or more drugs can be necessary $[8,9]$. All chemical agents produce collateral effects like nausea, metallic taste, yellow pigmentation of the skin, hepatic damage, inefficacy in the treatment, and resistance [10]. Actually research studies focused on the search of new and better drugs against Giardia intestinalis are made in endemic areas, follow strategies to develop giardicides, and reevaluate the characteristics of existent drugs [11].

Two major reasons to search new drugs are the increment of resistant strains and the need to give alternatives in the Giardia treatment with only one dose, high efficiency, and less side effects; natural medicine is a viable alternative.

Some natural products developed to increasing antigiardial activity are alcoholic extracts of ancestral plants used as natural medicine in Africa and in India an immunomodulated drug obtained from Pippali Rasayana produced up 


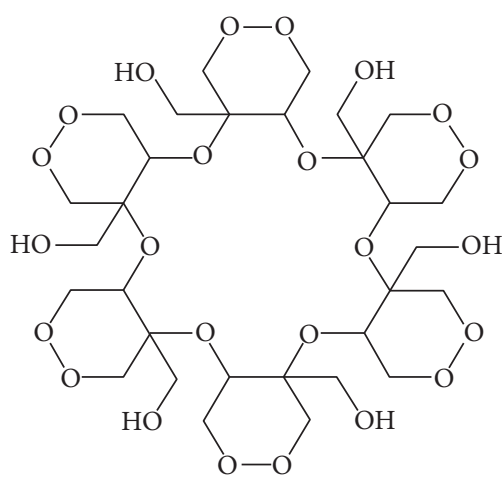

(a)

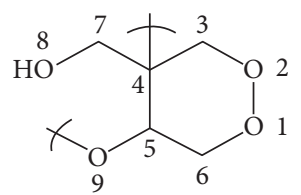

(b)

FIGURE 1: Chemical structure of (a) kramecyne (cyclic polymer) and (b) monomer [12].

to $98 \%$ recovery from the infection [13]. In Cuba, the most studied natural product with giardiasic activity is the propoleum obtained from bees because of its flavonoids, getting up to $60 \%$ healing efficiency versus $40 \%$ of tinidazole; this product is easy to obtain and without side reactions [14].

In Metropolitan University of Mexico, a research team has isolated a methanolic extract from Krameria cytisoides, a plant collected in a central region of Mexico and frequently used to treat stomachache and other gastrointestinal affections [15]. The compound called kramecyne presents a chemical structure of a polymer of six monomers of cyclic peroxide (Figure 1), which was determined by Infrared (IR) spectrum, magnetic nuclear resonance (MNR), and mass spectrometry (MS) and elemental analysis (http://www .freepatentsonline.com/WO2013077719.html). This product exhibits anti-inflammatory activity and does not appear to cause cell damage even to $5000 \mathrm{mg} / \mathrm{kg}$ [12]. Kramecyne is suspected to have antiprotozoan activity and it has been evaluated for the ability to kill several protozoan parasites including Giardia intestinalis. Our preliminary studies that suggest antigiardial ability of kramecyne and to evaluate the mechanism of action of this compound we evaluate by molecular techniques some vital genes in its structure, differentiation, and metabolism that could probably be a target for action.

The objective of this work was to determine the therapeutical effect of kramecyne over Giardia intestinalis trophozoites in vitro and in vivo and analyze the expression of genes: ERK1, ERK2, and AK on treated trophozoites by Real Time Polymerase Chain Reaction (RTPCR).

\section{Material and Methods}

\subsection{Effect In Vitro}

2.1.1. Kramecyne Solution. Kramecyne, a compound isolated from Krameria cytisoides, was obtained and kindly provided by Dr. Salúd Pérez Gutierrez from Biological Systems Department of UAM Xochimilco. From original extract of kramecyne, solutions diluted in TYI-S-33 media [16] were prepared to obtain $0,20,40,80,160$, and $320 \mu \mathrm{g} / \mathrm{mL}$.
2.1.2. Reference Strains of Giardia. The strains of Giardia intestinalis used in this study were P-I (ATCC ${ }^{\circledR} 30888,1971$ ) and WB (ATCC ${ }^{\circledR}$ 30957, 1983), both isolated from infected symptomatic patients, the first one in USA and the last one in Afghanistan. Both were cultured to $37^{\circ} \mathrm{C}$ and $5 \%$ of $\mathrm{CO}_{2}$ in TYI-S-33 media complemented with fetal bovine serum $10 \%$ and bovine bile $1.0 \mathrm{mg} / \mathrm{mL}$.

2.1.3. Median Lethal Dose $\left(L D_{50}\right)$ Determination. The concentration that inhibits $50 \%$ of parasite growth was determined as follows. Axenically cultured Giardia trophozoites (P-I and WB strains) were collected in logarithmic growth phase of a culture incubated at $37^{\circ} \mathrm{C}$ for $72 \mathrm{~h}$, the tubes are placed on ice bath for 10 minutes, and then concentration of parasites was adjusted to $1 \times 10^{6} / 0.5 \mathrm{~mL}$ by counting with Neubauer chamber. Trophozoites suspension was put to each tube containing $10 \mathrm{~mL}$ of medium and specific concentrations of the extract $(0,20,40,80,160$, and $320 \mu \mathrm{g} / \mathrm{mL})$ and incubated for $72 \mathrm{~h}$ at $37^{\circ} \mathrm{C}$. After this time the suspensions are placed back on ice for 5 minutes and centrifuged at $2500 \times \mathrm{g}$ during $10 \mathrm{~min}$; the number of viable trophozoites stained with trypan blue was determined by counting in Neubauer chamber. In addition, the same assay was performed using the P-I strain of Giardia and a modified variant resistant to albendazole P-I(r); both incubated each concentration used for kramecyne but instead with albendazole $(0,20,40,80$, 160 , and $320 \mu \mathrm{g} / \mathrm{mL}$ ), the test was carried out under the same conditions of time and temperature and the harvest and count was carried out in the same manner as mentioned above. Each count was performed in triplicate and $\mathrm{LD}_{50}$ value was determined [17].

\subsection{Effect In Vivo}

2.2.1. Cyst Purification. From feces obtained from children, Faust coproparasitoscopico analysis (CPS) was carried out for determining the presence of Giardia cysts. Feces were fully diluted with distilled water and filtered through gauze and the filtrate was stored at $4^{\circ} \mathrm{C}[18]$.

Cysts were purified from filtered human feces by sucrose gradients (Sigma S9378) as follows: $5 \mathrm{~mL}$ of stool filtrate was 
completed to $14 \mathrm{~mL}$ with distilled water, spun at $400 \times \mathrm{g}$ for 5 minutes, and resuspended in distilled water. A volume of $1 \mathrm{M}$ sucrose with density $1.11 \mathrm{~g} / \mathrm{ml}$ was added and centrifuged at $400 \times \mathrm{g}$ for 5 minutes. The cysts were observed in sucrosewater interface; the presence of parasitic structures in layer was verified by microscopic observation. Cysts were washed and resuspended in $1 \mathrm{~mL}$ of distilled water to be counted in a Neubauer chamber [19].

2.2.2. Experimental Infection in Gerbils (Meriones unguiculatus). Mongolian gerbils that were 21 days old were randomly transferred to separate cages to form five groups of 6 gerbils weighing between 15 and $25 \mathrm{~g}$, parasite-free determined by CPS. Gerbils were inoculated in an intragastric way with $1 \times$ $10^{6}$ purified cysts. After 5 days, stool samples were collected daily for CPS examination, until gerbils were positive to Giardia cysts in feces. They were kept under animal room conditions with food and water ad libitum all the time [20]. Additionally two more groups were included; as controls, in the first one, all the animals were kept free of infection and in the second one, the gerbils were infected but they were not treated with kramecyne.

2.2.3. Kramecyne Administration. When Giardia cysts were observed in feces, kramecyne was administered orally at concentrations of $40,320,450,500$, and $750 \mu \mathrm{g} / \mathrm{Kg}$ of weight during 5 days. CPS analysis was made daily until day 26 after inoculation. Animals were sacrificed by cervical dislocation and the entire small intestine was resected and opened longitudinally; the gut contents were scraped with a scalpel into a disposable Petri dish containing PBS buffer. The content of Petri dish was observed by microscopy to search Giardia trophozoites.

\subsection{Molecular Study}

2.3.1. Kramecyne Solutions. Kramecyne solutions were prepared from the original extract of kramecyne, to obtain final concentrations of $0,20,40,80$, and $160 \mu \mathrm{g} / \mathrm{mL}$.

2.3.2. Growth Inhibition Assay. Giardia trophozoites were collected in logarithmic growth phase as mentioned earlier to obtain a concentration of $1 \times 10^{6} / 0.5 \mathrm{~mL}$ by counting with Neubauer chamber. This parasite suspension was added to each tube with $2.5 \mathrm{~mL}$ of the culture medium and the specific concentration of the extract $(0,20,40,80$, and $160 \mu \mathrm{g} / \mathrm{mL}$, resp.) in triplicate. A comparison control using $1 \times 10^{6}$ trophozoites and $200 \mu \mathrm{g}$ albendazole was included. Treated cultures were incubated for $24 \mathrm{~h}$ at $37^{\circ} \mathrm{C}$.

2.3.3. RNA Extraction. After incubation, treated trophozoite suspension was used to obtain total RNA using RNAqueous kit (Cat. \# AM1912, Ambion) according to manufacturer instructions. Two-hundred microliters of lysis-binding buffer was added to each sample in order to disrupt the cells. Samples were then mixed by vortex and allowed to stand at room temperature for $5 \mathrm{~min}$ with $200 \mu \mathrm{L}$ of $64 \%$ ethanol; then it was passed through a column and two washes were done to remove contaminating salts; total RNA was eluted using
$30 \mu \mathrm{L}$ of heat elution buffer and the eluate was transferred to a new microcentrifuge tube. Eluted RNA was stored at $4^{\circ} \mathrm{C}$ after DNase treatment to degrade contaminating DNA.

2.3.4. cDNA Synthesis. cDNA was synthesized by reverse transcription adding $10 \mu \mathrm{L}$ of RNA using the amplification program: $37^{\circ} \mathrm{C}$ for $60 \mathrm{~min}, 70^{\circ} \mathrm{C}$ for $10 \mathrm{~min}, 22^{\circ} \mathrm{C}$ for $1 \mathrm{~min}$, and $4^{\circ} \mathrm{C}$. DNA concentration was estimated by measuring the absorbance at $260 \mathrm{~nm}$ (using the relationship that an $A_{260}$ of $1.0=50 \mu \mathrm{g} / \mathrm{ml}$ pure dsDNA). Integrity was observed in $1 \%$ agarose gel electrophoresis.

2.3.5. Design of Oligonucleotides. Oligonucleotides were designed using the software primer 3 [21] and based on the sequence of genes reported in the GenBank (https://www .ncbi.nlm.nih.gov/genbank/): extracellular signal-regulated kinase 1 (ERK1, gi|25527267): ERK1F ( $5^{\prime}$-CAGAATTGCGTCGGAT- ${ }^{\prime}$ ) and ERK1R ( $5^{\prime}$-AGGCTCGTCAGACTCATCGT-3'); extracellular signal-regulated kinase 2 (ERK2, gi25527281): ERK2F (F5 ${ }^{\prime}$-AATCCCAACAAGCGACTGAC$\left.3^{\prime}\right)$ and ERK2R ( $5^{\prime}$-GCGGATCTCCTTCTTTTTCC- $\left.{ }^{\prime}\right)$; adenylate cyclase (AK, gi|639927): AKF (5'-TTGGCTTTTGGATGGATTTC- $\left.3^{\prime}\right)$ and AKR (5'-CTTCTCTGTCGTCGGTCCTC- $3^{\prime}$ ). To test the capacity of amplification, a polymerase chain reaction (PCR) was made from $100 \mathrm{ng}$ of cDNA with PCR Master Mix (Promega) and the amplification program of initial denaturation at $94^{\circ} \mathrm{C}$ followed by 30 cycles at $94^{\circ} \mathrm{C}$ for $30 \mathrm{~s}$, an alignment step at $50-60^{\circ} \mathrm{C}$ for $30 \mathrm{sec}$, an extension step at $72^{\circ} \mathrm{C}$ for $30 \mathrm{~s}$, and a final extension of $72^{\circ} \mathrm{C}$ for $5 \mathrm{~min}$. The amplified products were resolved by $1.5 \%$ agarose gel electrophoresis, which was stained with ethidium bromide and visualized under UV illumination.

2.3.6. $q R T-P C R$. The mixture was prepared by using Maximum SYBR Green qPCR Master Mix (Thermo Fisher Scientific, USA), in a $15 \mu \mathrm{L}$ reaction mix, according to manufacturer instructions: Master Mix 1x, $0.1 \mathrm{nM}$ of ROX solution, $0.3 \mu \mathrm{M}$ of each primer, and $300 \mathrm{ng}$ of cDNA. Subsequently the reaction mixture was distributed into optical tubes and put in the thermal cycler (Agilent Technologies Stratagene, USA) with following two-step cycles protocol conditions: initial denaturation 10 minutes at $95^{\circ} \mathrm{C}$, followed by 40 cycles at $95^{\circ} \mathrm{C}$ for $15 \mathrm{~s}$ and an alignment at $60^{\circ} \mathrm{C}$ for $1 \mathrm{~min}$ over final extension $95^{\circ} \mathrm{C}$ per $1 \mathrm{~min}$ and $60^{\circ} \mathrm{C}$ for 30 seconds (ERK1 and ERK2). For AK the program was the same except for alignment temperature that was $56^{\circ} \mathrm{C}$.

2.4. Statistical Analysis. $\mathrm{LD}_{50}$ was determined graphically plotting a simple graphic representation of the concentration dose of kramecyne and \% of viability after incubation. Value of $50 \%$ was obtained by data correlation taking into account the average of the values performed in triplicate. For results of RTPCR the value of $p$ was determined for a test of significance $Z$ with a significance level of 0.05 .

2.5. Ethical Considerations. This study respects the copyright international. All involved people have been notified and they agree. Recollection of plants is according to norms 


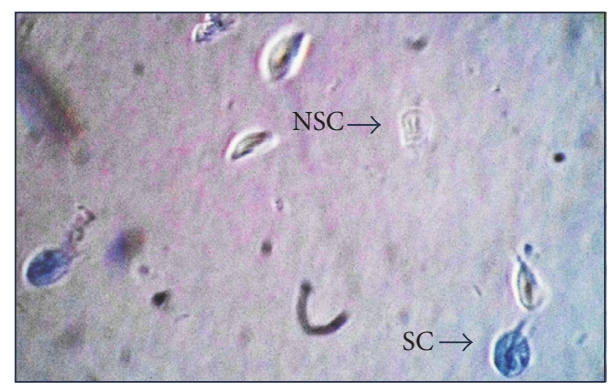

FIGURE 2: Trophozoites after treatment with $80 \mu \mathrm{g} / \mathrm{mL}$ of kramecyne stained with trypan blue dye. Preparation allows differentiating dead cells (in blue; SC) and transparent living cells (NSC). No structural damage is observed caused by contact with kramecyne. Olympus $\mathrm{BH}$ (40x).

of biodiversity conservation and we follow the NOM-062ZOO-1999 of safety management of animals. It had been approved by local ethical and biosecurity committee of the institution.

\section{Results and Discussion}

In this study the antigiardial effect of kramecyne on Giardia trophozoites growth and the expression of some vital genes for the structure, differentiation (ERK1 and ERK2), and metabolism (AK) of Giardia intestinalis was determined.

Figure 1 exhibits the structure of kramecyne, molecule obtained from the Krameria cytisoides methanolic extract and characterized in that it is a cyclic polymeric peroxide which is formed by a monomer which is bonded by atoms 4 and 9 (http://www.freepatentsonline.com/WO2013077719.html). This molecule was studied to evaluate the capacity to inhibit Giardia growth.

After treatment of axenic culture of Giardia with different concentrations of kramecyne, trypan blue staining allowed counting cells and also determining the proportion of viable and nonviable cells; Figure 2 shows blue-stained cells, indicating that the membrane of a nonviable cell has been permeated and allowed to enter the dye; in addition the staining allows observing that trophozoites did not appear to undergo structural modification by action of kramecyne; trophozoites did not lose their size and shape and did not show damage in nucleus structure, although ultrastructural studies are necessary to determine damage in a more specific way.

$\mathrm{LD}_{50}$ was observed at concentration of $40 \mu \mathrm{g} / \mathrm{mL}$, in both P1 and WB strains, which means that the fifty percent of Giardia trophozoites are killed at this concentration; both reference strains exhibited similar behavior when cultured with a kramecyne concentrations gradient (Figure 3). These results were compared with the effect of albendazole in the PI strain and a strain resistant to albendazole; although the $\mathrm{LD}_{50}$ is much lower than the kramecyne value, its homologue resistant to this drug offers a $\mathrm{LD}_{50}$ value of $70 \mu \mathrm{g} / \mathrm{mL}$, and the presence of resistant strains in human infections requires administering higher doses of drugs and for longer period of time, which justifies the use of more

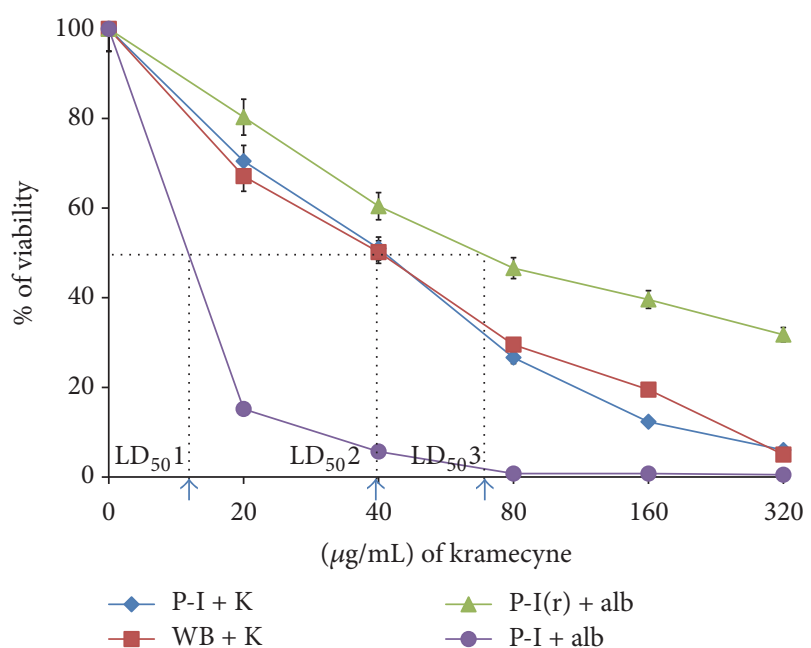

FIGURE 3: Results of effect in vitro, percentage of inhibition of two strains (P-I and WB ) of Giardia intestinalis axenically cultured treated with different concentrations of kramecyne $(\mathrm{K}), \mathrm{LD}_{50} 2$ value $=40 \mu \mathrm{g} / \mathrm{mL}$ for both strains. Percentages of inhibition of P-I and P$\mathrm{I}(\mathrm{r})$ are also observed $\left(\mathrm{LD}_{50} 1=12\right.$ and $\mathrm{LD}_{50} 3=70 \mu \mathrm{g} / \mathrm{mL}$, resp.).

efficient alternatives. Several studies have been conducted to evaluate antiparasitic properties of plant extracts against Giardia intestinalis; Ponce-Macotela et al. in 2006 [22] studied the effect of oregano (Lippia berlandieri) ethanolic extracts against Giardia trophozoites at concentrations ranging from 58 to $588 \mu \mathrm{g}$ and demonstrated ultra-structural lesion in trophozoites, losing shape, size, and damage to the nucleus. Similar studies have been reported to different natural extracts of plants; Yucca baccata exhibited effective antigiardial activity in the proximal segment similar to metronidazole [23]. The dichloromethane fraction of peppermint presented antigiardial activity in vitro with an IC(50) of $0.75 \mu \mathrm{g} / \mathrm{mL}$ causing several alterations on plasma membrane surface of the parasite and inhibited the adhesion of $G$. intestinalis trophozoites [24], while another study concluded that water soluble extracts of blueberries can kill G. intestinalis trophozoites and modify the cell morphology [25].

In vitro model was performed in triplicate to confirm the repeatability; this procedure is made in a controlled environment, so it was possible to determine the $\mathrm{LD}_{50}$ value. In vivo study showed an efficacy value on giardiasis elimination of infected gerbils; the results at different concentrations are represented in Table 1 . Concentrations used in this experiment were determined from the value of $\mathrm{LD}_{50}$ which was 40 and up to a concentration of $750 \mu \mathrm{g} / \mathrm{Kg}$ of weight. Experimental groups of six gerbils were observed to obtain that, with $320 \mu \mathrm{g} / \mathrm{Kg}$ of weight, we obtained $80 \%$ of efficiency to eliminate the experimental infection, but at 450,500, and $750 \mu \mathrm{g} / \mathrm{Kg}$ of weight this efficiency is lower (60\%); it means that just two of six gerbils got infection-free (Table 1). In the control group the uninfected gerbils kept without Giardia until the end of experiment, and the infected/untreated gerbils remained parasitized until the 26th day after inoculation. In this work and in many cases published before the results seem variable and determined by several factors as biological 
TABLE 1: Results of effect in vivo. Efficiency of treatment of kramecyne over infected gerbils with experimental giardiasis. The chronological procedure in days is shown. Nontreated gerbils remain infected until day 26 and they were also euthanized.

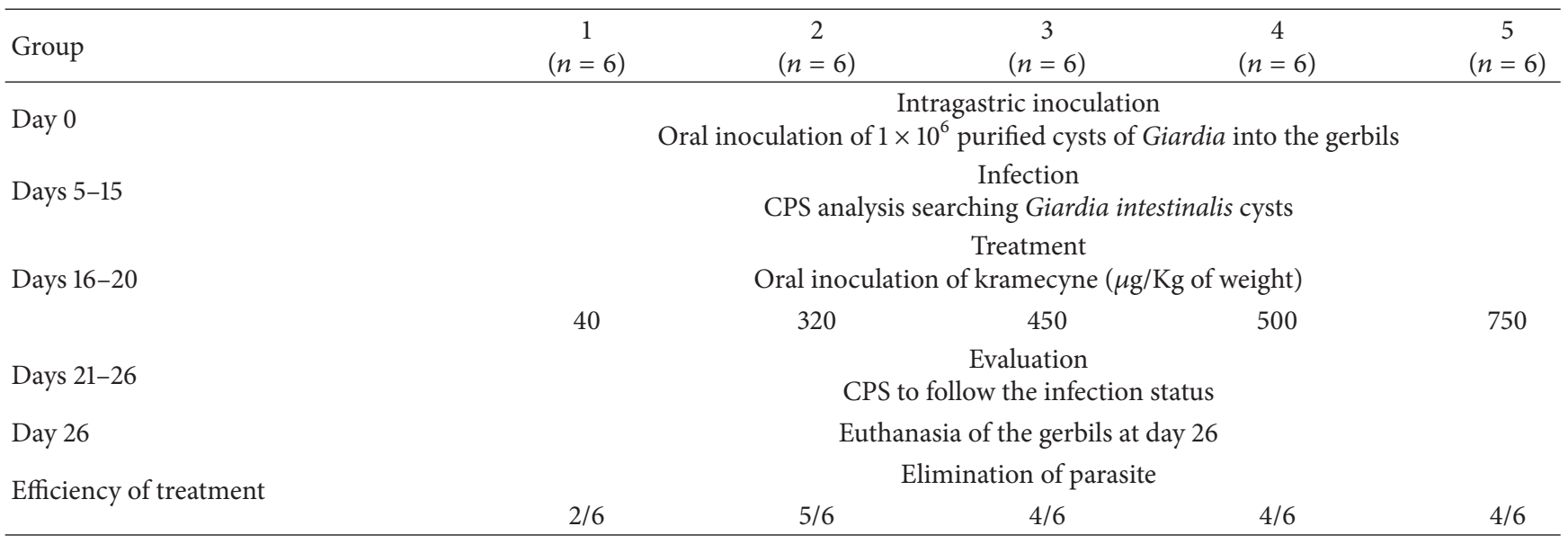

variability of animal model; this could be minimized by an increment in the number of animal specimens tested by group. After treatment with kramecyne the content of the intestine was analyzed microscopically to evaluate the presence of trophozoites and to determine visible alterations in the intestine; none of the observations presented changes or differences between intestines of treated gerbils respecting nontreated ones. The results obtained in vivo and in vitro present differences and they cannot be compared due to the conditions in which each of them is carried out. Results show antigiardial activity of kramecyne in vitro and in vivo; it suggests that this compound could have a potential value as therapeutic agent against Giardia intestinalis infections. But it is important to know the mechanism of action by which this compound acts on Giardia.

We analyzed three genes: adenylate cyclase (AK), corresponding to phosphorus-oxygen lyase activity protein on cyclic nucleotide biosynthetic process and intracellular signal transduction [26], and two members of the MAPK family: extracellular signal-regulated kinases 1 and 2 (ERK1 and ERK2), which play a critical role in trophozoite differentiation into cysts $[27,28]$.

The Real Time PCR was performed to determine whether the expression of genes was affected or modified after treatment. When comparing ERK1 and AK expression levels against the untreated control, no statistical significance is observed. While with ERK2 significant difference $(p=$ 0.04 ) is observed comparing with nontreated cells, and it is necessary to study more deeply into this gene and others related in order to establish if there are changes at this level in the trophozoite in contact with kramecyne (Figure 4).

The antigiardiasic activity of kramecyne has been verified but its mechanism of action is still unclear; for this reason it is necessary to realize studies with other genes or at the level of proteins to know how and which molecules are involved in the action of kramecyne over trophozoites.

Kramecyne is a potent inhibitor of inOS, COX-2, NO, TNF- $\alpha$, and IL- 6 production at the transcriptional level in

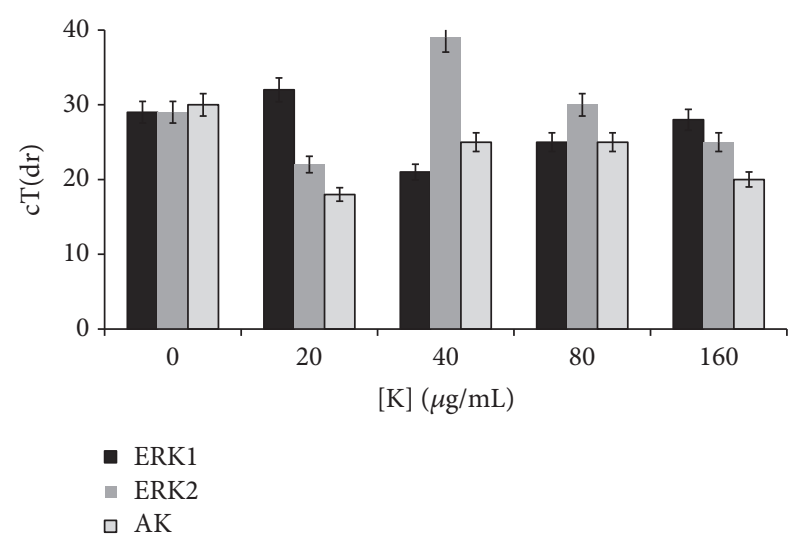

FIGURE 4: Graph of kramecyne concentration versus Ct values showing results of the expression determined by Real Time PCR reaction for the genes ERK1 $(z=0.5)$, ERK2 $(z=0.04)$, and AK $(z=0.99)$.

LPS-stimulated macrophages, which gives anti-inflammatory properties by involving ionic interchange of cell [29], and perhaps this feature is involved in the mechanism that causes the death of Giardia trophozoites in a similar way to the mechanism of omeprazole, which has been demonstrated to have potential for inhibiting giardial glycolytic enzyme triosephosphate isomerase (GiTIM) in a species-specific manner, with a deleterious effect only when targeting Cys 222 and killing Giardia trophozoites [30].

\section{Conflicts of Interest}

The authors declare that they have no conflicts of interest.

\section{Acknowledgments}

This work was supported by Federal Funds 2016 (Grant no. HIM-2016008). 


\section{References}

[1] Sistema Único de información para la Vigilancia Epidemiológical Dirección General Adjunta de Epidemiología, SSA. Anuario de Morbilidad, 2015.

[2] F. M. Rosado-García, M. Guerrero-Flórez, G. Karanis, M. D. Hinojosa, and P. Karanis, "Water-borne protozoa parasites: The Latin American perspective," International Journal of Hygiene and Environmental Health, vol. 220, no. 5, pp. 783-798, 2017.

[3] R. H. Gilman, K. H. Brown, G. S. Visvesvara, G. Mondal, B. Greenberg, R. B. Sack et al., "Epidemiology and serology of Giardia intestinalis in a developing country: Bangladesh," Transactions of the Royal Society of Tropical Medicine and Hygiene, vol. 79, pp. 469-473, 1985.

[4] R. Gilman, E. Miranda, G. Marquis, M. Vestegui, and H. Martinez, "Rapid reinfection by giardia lamblia after treatment in a hyperendemic third world community," The Lancet, vol. 331, no. 8581, pp. 343-345, 1988.

[5] P. S. Sullivan, H. L. Dupont, R. R. Arafat et al., "Illness and reservoirs associated with Giardia lamblia infection in rural Egypt: The case against treatment in developing world environments of high endemicity," American Journal of Epidemiology, vol. 127, no. 6, pp. 1272-1281, 1988.

[6] L. Jokipii and A. M. M. Jokipii, "Comparison of four dosage schedules in the treatment of giardiasis with metronidazole," Infection, vol. 6, no. 2, pp. 92-94, 1978.

[7] M. Bowers, "Nitazoxanide for cryptosporidial diarrhea," BETA bulletin of experimental treatments for AIDS: a publication of the San Francisco AIDS foundation, pp. 30-31, 1998.

[8] T. V. Murphy and J. D. Nelson, "Five v Ten Days' Therapy With Furazolidone for Giardiasis," American Journal of Diseases of Children, vol. 137, no. 3, pp. 267-270, 1983.

[9] R. A. Thompson, "Giardiasis: Conceptos modernos sobre su control y tratamiento," Annales Nestlé (Ed. española), vol. 66, no. 1, pp. 23-29, 2008.

[10] S. J. Lerman and R. A. Walker, "Treatment of Giardiasis: Literature Review and Recommendations," Clinical Pediatrics, vol. 21, no. 7, pp. 409-414, 1982.

[11] W. A. Petri Jr., "Treatment of giardiasis," Current Treatment Options in Gastroenterology, vol. 8, no. 1, pp. 13-17, 2005.

[12] S. Pérez-Gutiérrez, E. Sánchez-Mendoza, D. MartínezGonzález, M. A. Zavala-Sánchez, and C. Pérez-González, "Kramecyne - A new anti-inflammatory compound isolated from Krameria cytisoides," Molecules, vol. 17, no. 2, pp. 2049-2057, 2012.

[13] A. K. Agarwal, M. Singh, N. Gupta et al., "Management of giardiasis by an immuno-modulatory herbal drug Pippali rasayana," Journal of Ethnopharmacology, vol. 44, no. 3, pp. 143146, 1994.

[14] C. Miyares, I. Hollands, C. Castañeda et al., "Ensayo terapéutico con un preparado a base de propóleos propolisina en la giardiasis del humano," Acta. Gastroenterol. Latinoam, vol. 18, pp. 195-201, 1988.

[15] A. Sánchez-González, D. Granados-Sánchez, and R. SimónNabor, "Uso medicinal de las plantas por los otomíes del municipio de Nicolás Flores Hidalgo México," Rev. Chapingo. Ser. Hortic, vol. 14, pp. 271-279, 2008.

[16] D. B. Keister, "Axenic culture of Giardia lamblia in TYI-S-33 medium supplemented with bile," Transactions of the Royal
Society of Tropical Medicine and Hygiene, vol. 77, no. 4, pp. 487488, 1983.

[17] J. A. Santos, V. Valin, and A. S. Ferrão-Filho, "Determination of the lethal doses $\mathrm{LD}_{50}$ and $\mathrm{LD}_{90}$ of Euphorbia splendens var. hislopii latex on Physa cubensis Pfeiffer," Ambi-Agua, Taubaté, 2012.

[18] J. C. Carl, "Experimental infection with giardia lamblia in rats," The Journal of Infectious Diseases, vol. 145, no. 4, pp. 495-498, 1982.

[19] J. F. Sauch, "Purification of Giardia muris cysts by velocity sedimentation," Applied and Environmental Microbiology, vol. 48, pp. 454-455, 1984.

[20] A. Arévalo, S. Duque, and R. S. Nicholls, "Experimental infection of the gerbil (Meriones unguiculatus) by Colombian isolates of Giardia duodenalis," Biomédica : revista del Instituto Nacional de Salud, vol. 25, no. 3, pp. 305-314, 2005.

[21] A. Untergasser, I. Cutcutache, T. Koressaar et al., "Primer3-new capabilities and interfaces," Nucleic Acids Research, vol. 40, no. 15, p. el15, 2012.

[22] M. Ponce-Macotela, Y. Rufino-González, A. González-Maciel, R. Reynoso-Robles, and M. N. Martínez-Gordillo, "Oregano (Lippia spp.) kills Giardia intestinalis trophozoites in vitro: Antigiardiasic activity and ultrastructural damage," Parasitology Research, vol. 98, no. 6, pp. 557-560, 2006.

[23] L. Quihui-Cota, R. León-Trujillo, H. Astiazarán-García et al., "Marked antigiardial activity of yucca baccata extracts: a potential natural alternative for treating protozoan infections," BioMed Research International, vol. 2014, Article ID 823492, 2014.

[24] F. Vidal, J. C. Vidal, A. P. R. Gadelha, C. S. Lopes, M. G. P. Coelho, and L. H. Monteiro-Leal, "Giardia lamblia: The effects of extracts and fractions from Mentha x piperita Lin. (Lamiaceae) on trophozoites," Experimental Parasitology emphasizes, vol. 115, no. 1, pp. 25-31, 2007.

[25] J.-P. Anthony, L. Fyfe, D. Stewart, G. J. McDougall, and H. V. Smith, "The effect of blueberry extracts on Giardia duodenalis viability and spontaneous excystation of Cryptosporidium parvum oocysts, in vitro," Methods, vol. 42, no. 4, pp. 339-348, 2007.

[26] J. J. Murtagh Jr., M. R. Mowatt, C.-M. Lee et al., "Guanine nucleotide-binding proteins in the intestinal parasite Giardia lamblia. Isolation of a gene encoding an $\sim 20-\mathrm{kDa}$ ADPribosylation factor," The Journal of Biological Chemistry, vol. 267, no. 14, pp. 9654-9662, 1992.

[27] J. G. Ellis IV, M. Davila, and R. Chakrabarti, "Potential involvement of extracellular signal-regulated kinase 1 and 2 in encystation of a primitive eukaryote, Giardia lamblia: Stagespecific activation and intracellular localization," The Journal of Biological Chemistry, vol. 278, no. 3, pp. 1936-1945, 2003.

[28] H.-Y. Lee, S. Hyung, N. Y. Lee, T.-S. Yong, S.-H. Han, and S.-J. Park, "Excretory-secretory products of Giardia lamblia induce interleukin-8 production in human colonic cells via activation of p38, ERK1/2, NF- $\kappa$ B and AP-1," Parasite Immunology, vol. 34, no. 4, pp. 183-198, 2012.

[29] E. Sánchez-Miranda, J. Lemus-Bautista, S. Pérez, and J. PérezRamos, "Effect of kramecyne on the inflammatory response in lipopolysaccharide- stimulated peritoneal macrophages," Evidence-Based Complementary and Alternative Medicine, vol. 2013, Article ID 762020, 2013. 
[30] H. Reyes-Vivas, I. De La Mora-De La Mora, A. CastilloVillanueva et al., "Giardial triosephosphate isomerase as possible target of the cytotoxic effect of omeprazole in Giardia lamblia," Antimicrobial Agents and Chemotherapy, vol. 58, no. 12, pp. 7072-7082, 2014. 


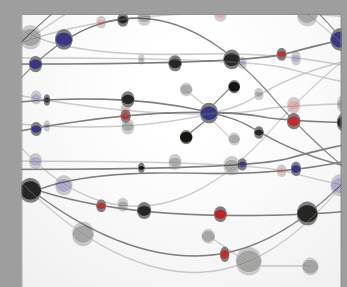

The Scientific World Journal
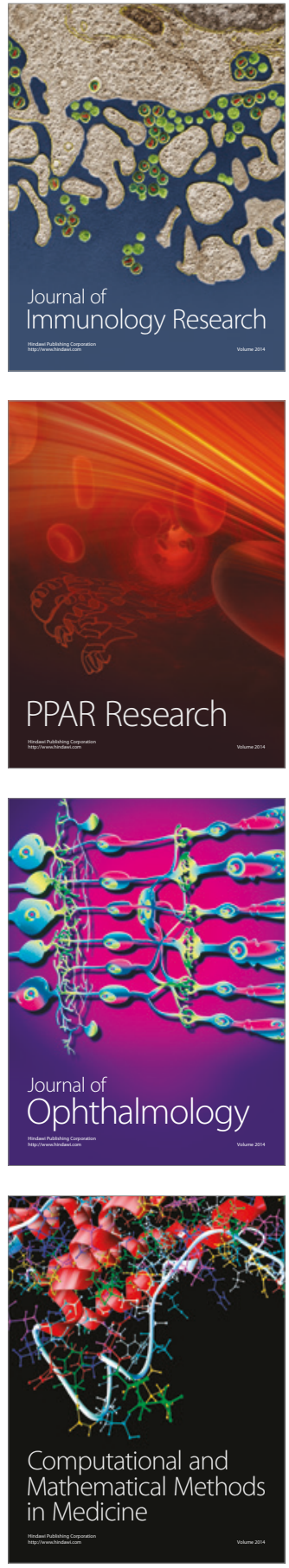

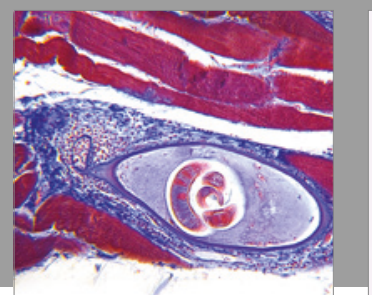

Gastroenterology Research and Practice
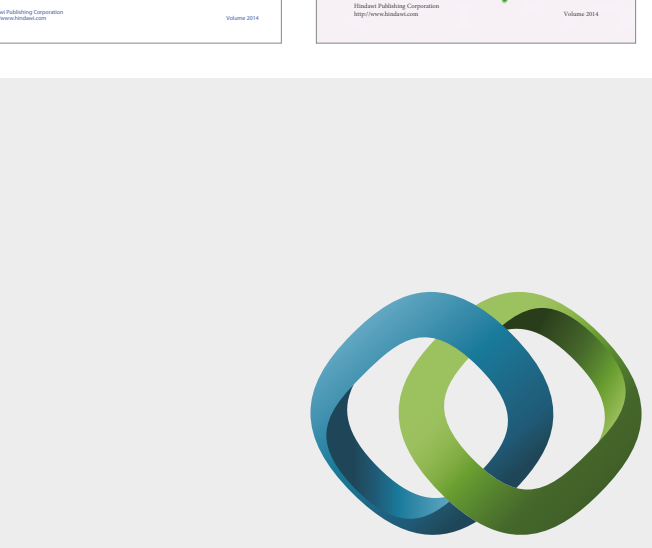

\section{Hindawi}

Submit your manuscripts at

https://www.hindawi.com
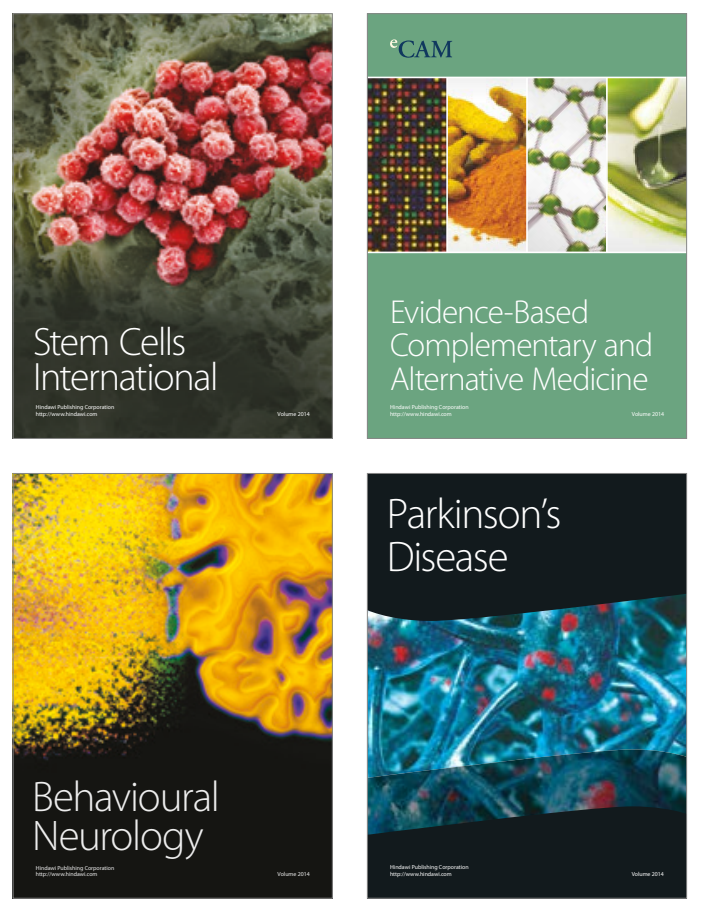
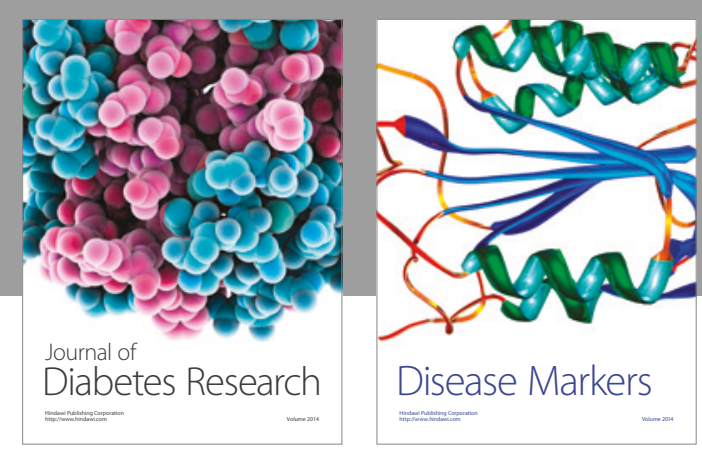

Disease Markers
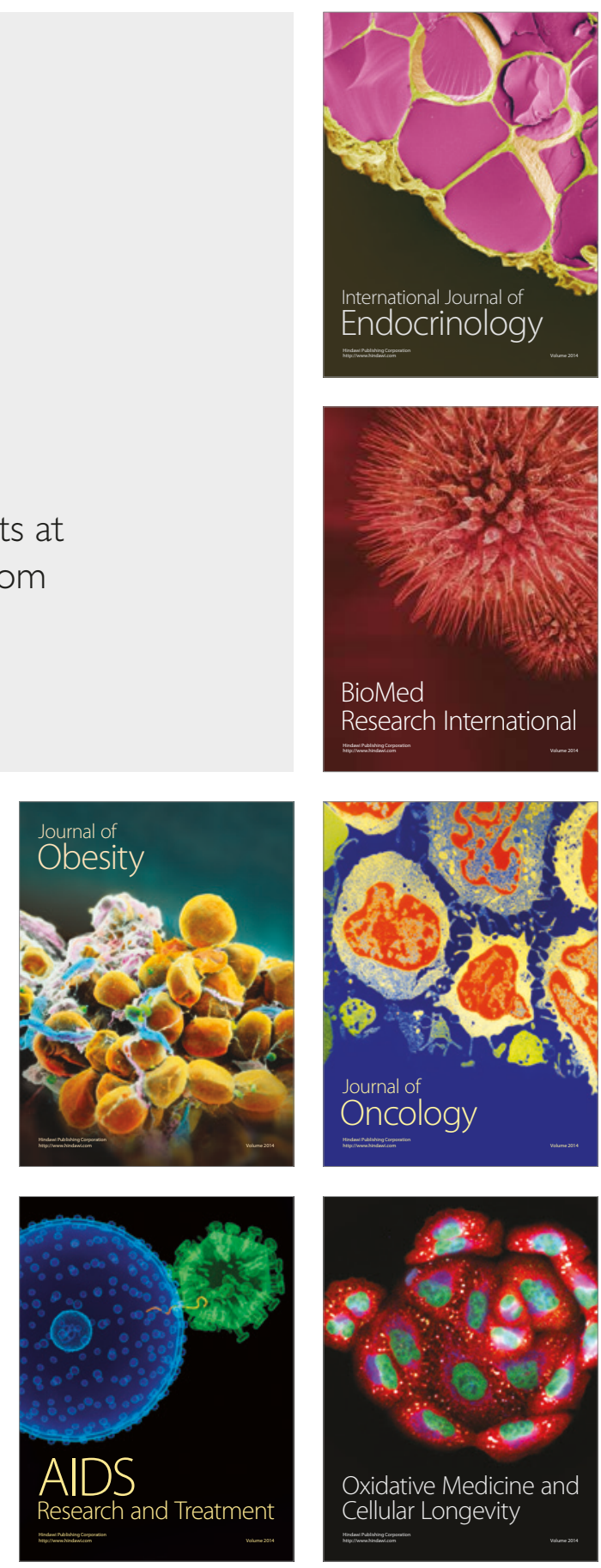